\title{
Preface
}

\section{Soil as an integrating factor between environmental components and agricultural production}

\author{
Adriana Reatto(1) and Renato Ferreira Passos ${ }^{(1)}$ \\ (1)Embrapa Informação Tecnológica, Parque Estação Biológica (PqEB), Avenida W3 Norte (Final), Caixa Postal 040315, CEP 70770-901 \\ Brasília, DF, Brazil. E-mail: adriana.reatto@embrapa.br, renato.passos@embrapa.br
}

\section{Introduction}

The central theme of this Thematic Issue on Soils is "Soil as an integrating factor between environmental components and agricultural production". From this central theme, the papers were divided into the three following sections, according to the major areas of knowledge addressed: Soil and Planning, Soil and Production, and Soil and Environment, as well as their connections (Figure 1).

In the section Soil as a support for Planning, priority was given to contributions that would increase the knowledge of the interrelations between soils and landscape components, and that addressed the implications of these interrelations for the strategic planning of land use, supported by geospatial tools. Issues such as soil characterization and digital mapping, precision agriculture, and zoning of environmental components - which are models that guide the sustainability of agricultural production - are discussed singly or together.

In the section Soil as an integrating factor of the Environment, priority was given to contributions on soil ecosystems and on environmental services, such as: soil's role in the landscape functioning; impacts of human activities on the provision and maintenance of environmental services; emission of greenhouse gases in various land uses; environmental quality in areas under remediation; and soil pollution.

In the section Soil as substrate for Production, priority was given to contributions on conservation tillage systems and their impacts on the quality of soil and water, including: studies with the quantification of the effects of management systems on the physical, chemical, and biological indicators of soil quality, highlighting their implications for soil and water conservation practices; studies with an integrative approach on the effects of soil biology, physics, and fertility on agricultural production; and studies that addressed the tropicalization of fertilizers, its implications on nutrient bioavailability, and its impacts on the environment.

The following is a summary of the papers published in each section of this Thematic Issue on Soils.

\section{Soil and Planning}

A schematic diagram of the topics discussed in the section on soil and its relation with planning is shown in Figure 2, and, for an overview of the research topics, a word cloud (in Portuguese) is presented, drawn from the use frequency of the terms employed in the papers within the section (Figure 3).

One of the great challenges posed by the advancing agricultural frontiers is the inclusion of light soils, mainly represented by Quartzipsamments and partly by Oxisols and Ultisols, in the production process. This section contains a review with the characterization, agricultural potential, and management perspectives of these soils, indicating the main research, extension, and technology transfer challenges faced in the expansion and consolidation of the new agricultural frontier, such as in the Matopiba region (Donagemma et al., p.1003). In association with the challenges posed to light soils, Oldomi et al., p.1283, address the irrigation management in a Quartzipsamment under different combinations of soil physico-hydraulic attributes, and determine the optimal number of management zones for an irrigated vineyard of Table vine, in the Brazilian semiarid region.

Another major research challenge discussed in this section is the development of models that can 


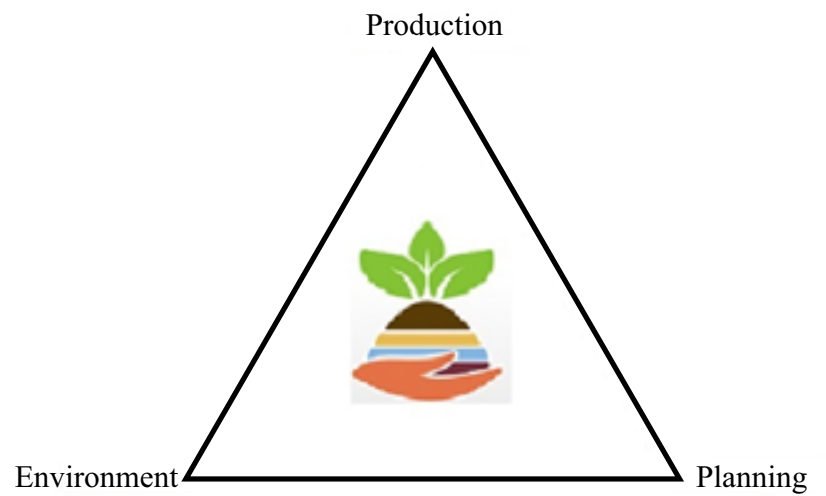

Figure 1. Conceptual illustration of this Thematic Issue on soils, with the three study sections on soil as an integrating factor between agricultural Planning, Environment, and Production. simply represent soil classes and attributes, as well as the complexity of the landscape. Information on the spatial distribution of these attributes culminates in landscape modeling, and is fundamental for formulating sustainable agricultural policies and for monitoring the impacts caused by the inappropriate use of this resource. Therefore, this number also includes: a contribution with pedometric techniques of digital soil mapping for predicting areas physiographically alike (Bagatini et al., p.1317); an evaluation of the performance of the Random Forest algorithm in predicting soil class distributions (Dias et al., p.1396); a discussion of the effect of the spatial resolution of the digital elevation model and of the efficiency of the

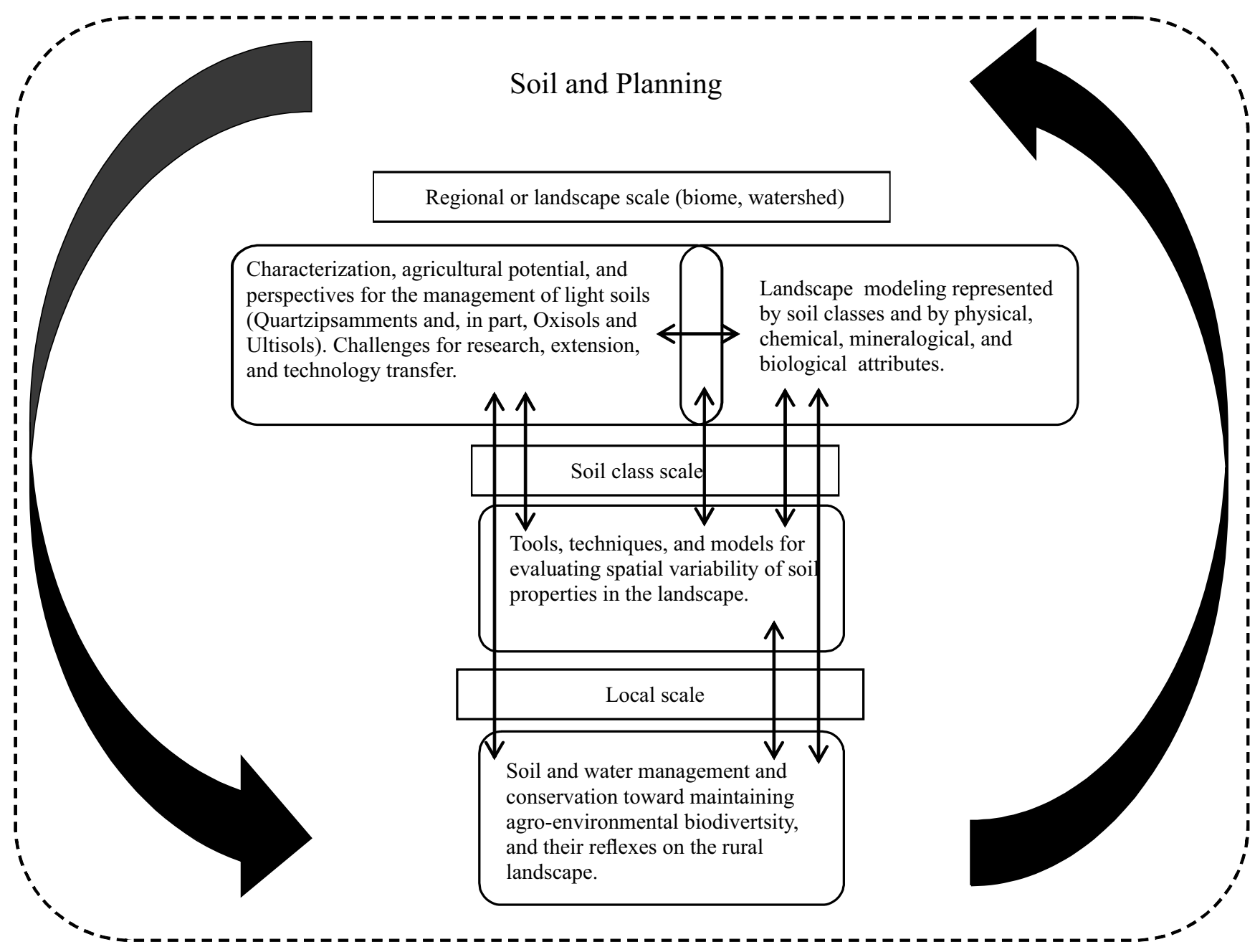

Figure 2. Themes addressed in the section Soil and Planning and their connections. 
Random Forest model on the prediction of the sand, clay, and organic carbon contents, using a reduced number of samples (Bhering et al., p.1359); a prediction of soil density from soil attributes commonly found in the soil profile analyses described in regional surveys (Carvalho Jr. et al., p.1428); and the application of the slice-wise algorithm and equal-area spline function for characterizing particle size distribution in hydromorphic soils (Pinheiro et al., p.1326).

Soils vary vertically and horizontally, which creates complex landscape spatial patterns. The understanding of soil spatial distribution is addressed in this issue, especially by assessing the spatial variability of soil attributes with geostatistical methods, such as regression kriging and ordinary kriging (Vasques et al., p.1371; Andrade et al., p.1386).

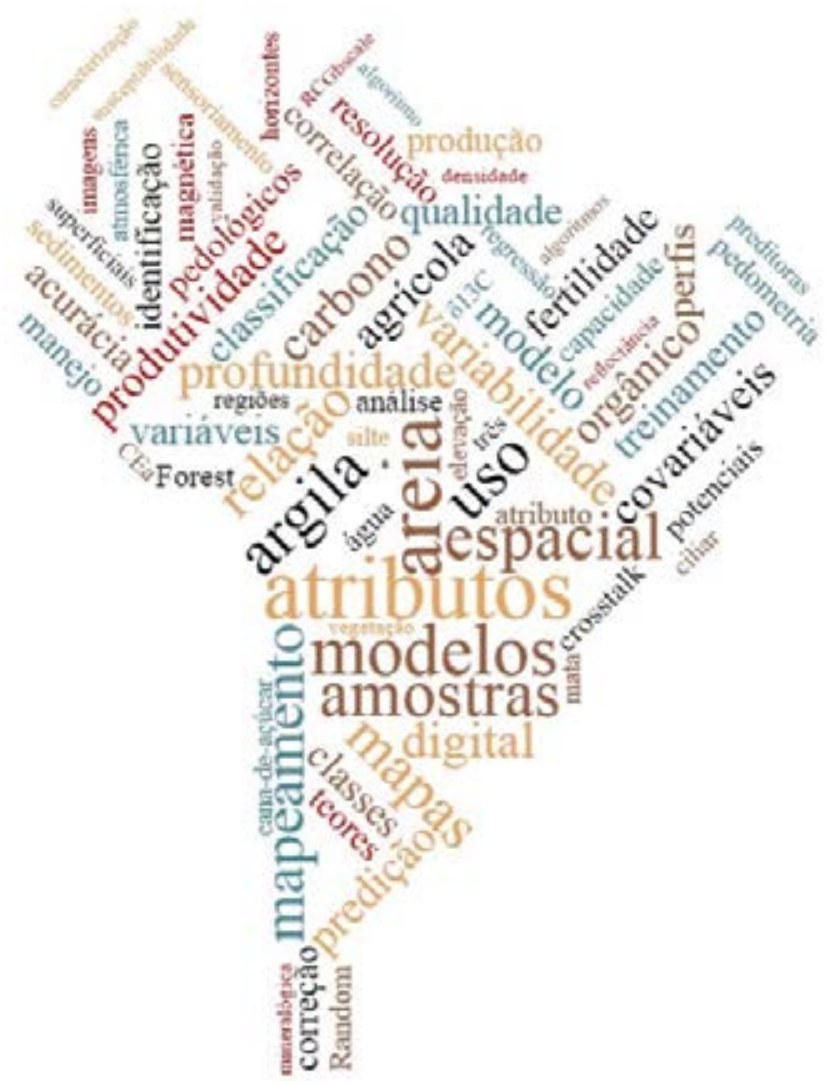

Figure 3. Word cloud, in Portuguese, drawn from the use frequency of the terms employed in the studies within the section Soil and Planning. The major terms were: attributes, models, sand, spatial, clay, use, maps, mapping, relationship, digital, carbon, prediction, covariates, and production.
The variability of soil classes can also be expressed with the prediction of soil chemical properties, from the evaluation of soil spectral information. Techniques such as near-infrared spectroscopy (NIRS) are used to predict forms of $\mathrm{P}, \mathrm{C}$, and $\mathrm{N}$ in Oxisols and Alfisols under different land uses (Felix et al., p.1405). Soil color is discussed in order to verify its potential in identifying areas with different potential for coffee production and for interference in the quality of coffee drink (Carmo et al., p.1261). As to the variability of soil properties, magnetic susceptibility is used to identify areas with different potentials for sugarcane production (Siqueira et al., p.1349). This variability of soil attributes, associated with sediment variability, allowed for the determination of the impact of water erosion on soil, and for pointing out inadequate soil uses and managements that result in reduced porosity and in changed balance in the infiltration/runoff relationship, in soils near riparian forests (Momoli et al., p.1295).

One of the constraints for a greater knowledge of natural resources is the low availability of cartographic information on a landscape scale $(1: 100,000$ or greater). Geoprocessing allows segmenting patterns, simulating processes, describing system dynamics, and predicting future scenarios using models. Therefore, geoprocessing tools allow, for example, to spatialize and to generalize pedological patterns of a particular area, in order to extrapolate them to other units of the geographical space, which conform to the same landscape pattern. In this section, there are also works on: the improvement of processing techniques of RapidEye satellite images in order to aid soil mapping of the "Mar de Morros" landscape pattern (Costa et al., p.1417); techniques for atmospheric and crosstalk corrections of data from the advanced spaceborne thermal emission and reflection radiometer (Aster) sensor, for mapping the mineralogy of soils from the Niquelândia Complex (Baptista et al., p.1272); and techniques for soil acidity spatialization in agricultural areas using the Veris 3100 on-the-go sensor (Corassa et al., p.1306).

Finally, this section provides a complementary contribution to the Brazilian System of Soil Classification, which is the characterization of surface diagnostic horizons of Inceptisols as to their $813 \mathrm{C}$ values, in high altitude regions (Dortzbach et al., p.1339).

Pesq. agropec. bras., Brasília, v.51, n.9, p.xi-xix, set. 2016 DOI: 10.1590/S0100-204X2016000900iii 


\section{Soil and Environment}

Soil as an integrating factor of the environment is referred to as the protagonist of many challenges, represented in Figure 4. In Figure 5, a word cloud (in Portuguese) is presented, drawn from the use frequency of the terms employed in the studies within the section.

The topics are initially distributed on a regional or landscape scale, in order to present an overview of how the soil is a provider of ecosystem services, indicating the challenges and opportunities for research and for the development of public policies related to agri-environmental sustainability in Brazil
(Prado et al., p.1021). In this scale, case studies exemplify the provision of ecosystem services in agricultural ecosystems and in Brazilian biomes, and propose a set of indicators for such services in order to monitor changes in agroecosystems (Turetta et al., p.1051). Soil eutrophication is addressed regarding remaining fragments of woody vegetation, adjacent to agricultural landscapes, according to their use intensity (Uzêda et al., p.1120). The soil filtering function is treated in an exploratory scale using the soil map of the Cerrado biome - 1:5,000,000 -, highlighting the most susceptible areas to groundwater contamination (Mingoti et al., p.1252).

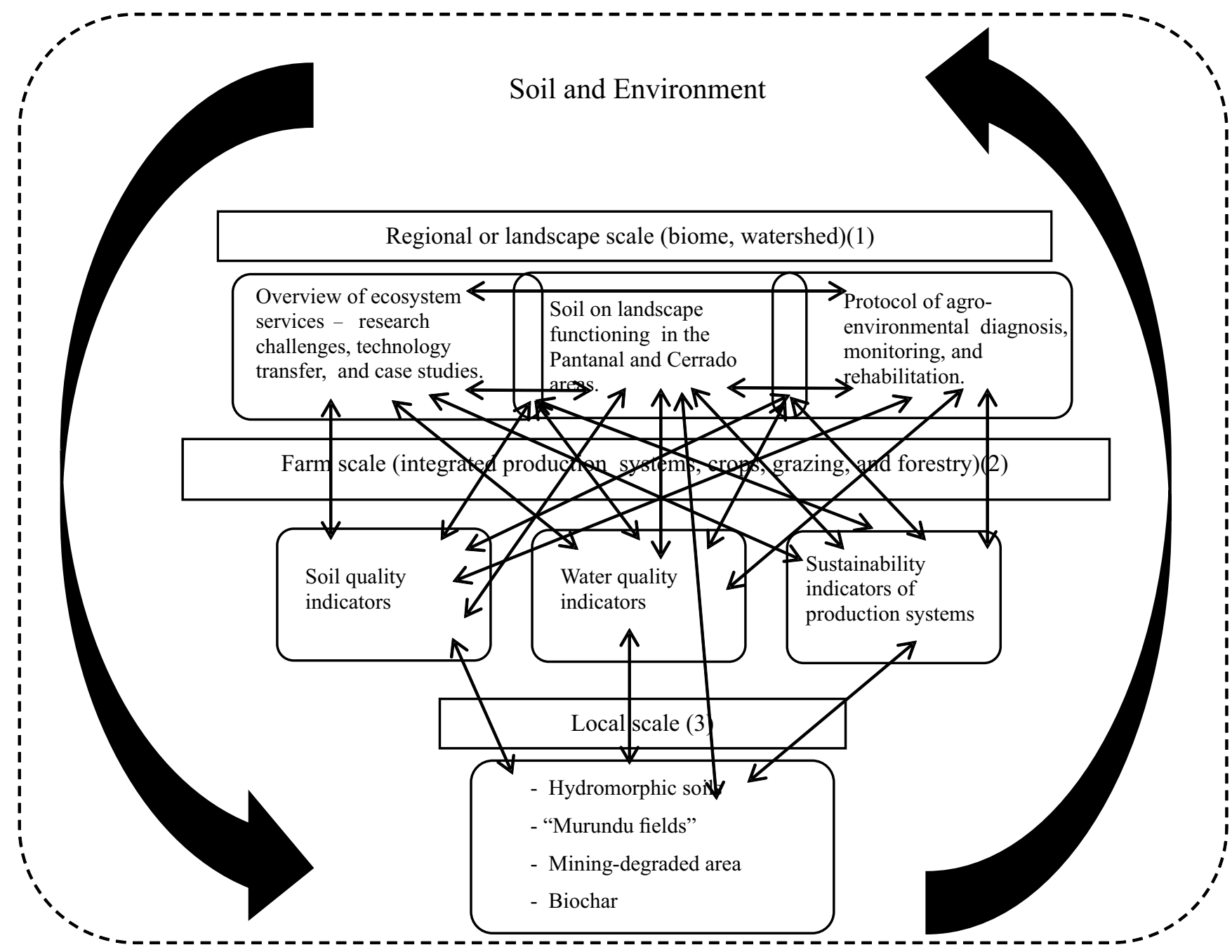

Figure 4. Themes addressed in the section Soil and Environment and their connections. Themes: 1, regional or landscape scale (biome, watershed); 2, farm scale (integrated production systems, crops, grazing, and forestry); and 3, local scale. 
Soil functioning in the landscape units of the Pantanal (Cardoso et al., p.1231) and soil carbon role in landscape functioning are also addressed (Alves et al., p.1241). Within this macroscopic scale, there is also a protocol for agri-environmental diagnosis, monitoring, and rehabilitation in a watershed (Vischi Filho et al., p.1099).

In a less comprehensive work scale, designated as a farm scale, issues related to integrated production systems, pastures, crops, and reforestation are presented, focusing on soil quality indicators, on water quality, and on the sustainability indicators of production systems. Pasture degradation levels are measured by various indicators linked with soil quality (Lisbôa et al., p.1184). Water quality indexes (WQI) associated with land use patterns in river basins -

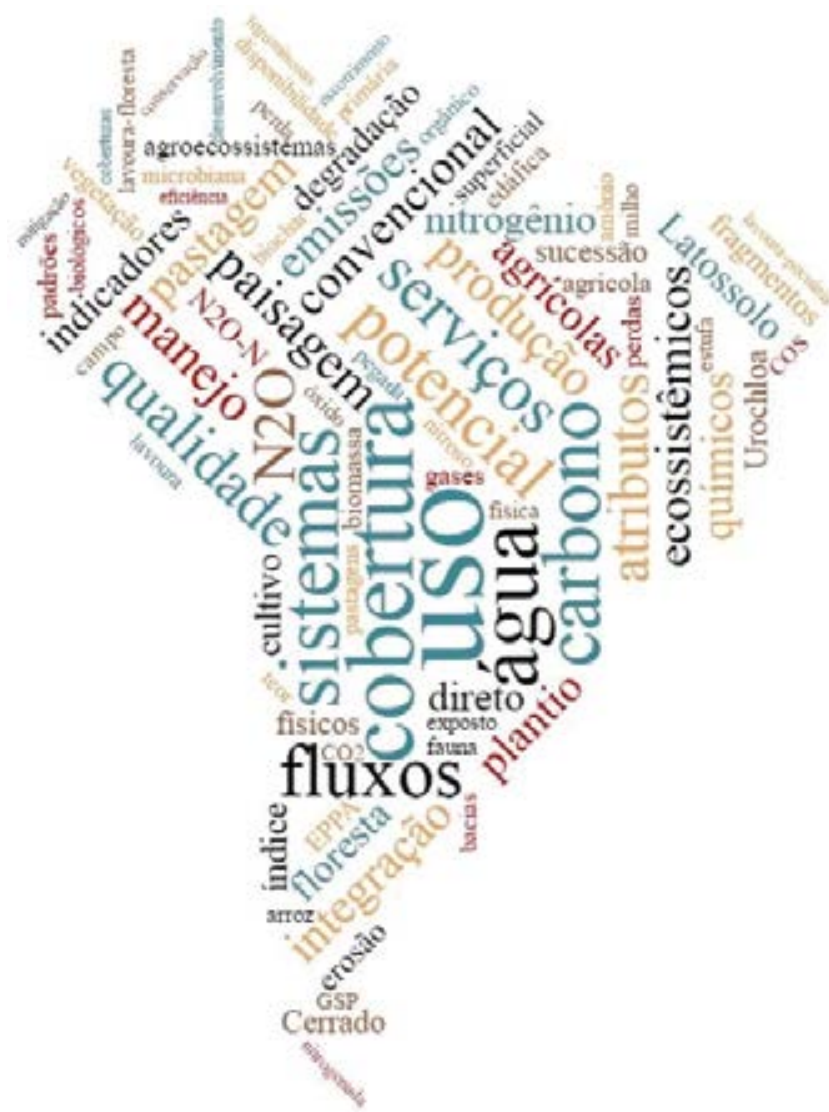

Figure 5. Word cloud, in Portuguese, drawn from the use frequency of the terms employed in the studies within the section Soil and Environment. The major terms were: use, cover, systems, carbon, flows, water, potential, $\mathrm{N}_{2} 0$, services, quality, emissions, management, landscape, ecosystem, conventional, and indicators. aiming at the management of water resources and of land use - are also a subject in this Thematic Issue (Gonçalves et al., p.1172).

The sustainability indicators of production systems are a recurring research theme in this scale. Biological and microbiological indicators are evaluated on production systems under no-tillage (Almeida et al., p.1140). Evaluations of soil and water losses show the high conservation potential of the integrated crop-livestock-forestry (ICLF) system compared with the conventional cropping system with soybean/corn rotation (Zolin et al., p.1223). Moreover, the life-cycle assessment in integrated and conventional production systems of irrigated common bean is used to check their impact on carbon footprint and on the efficiency of nitrogen fertilization (Carmo et al., p.1069). Phosphorus losses by surface runoff in agricultural areas are also evaluated in different soil classes (Bortolon et al., p.1088) to analyze the eutrophication risk of freshwater. The loss of soil and water is the object of a study with different farming systems and soil coverage levels, used as indicators for conservation systems (Almeida et al., p.1110). The potential of integrated production systems, such as ICLF, to mitigate the emissions of $\mathrm{N}_{2} \mathrm{O}$ is also analyzed (Nogueira et al., p.1156). Furthermore, the impacts of winter cover crops and intermittent soil drainage in irrigated rice are assessed with indicators related to $\mathrm{CH} 4$ and $\mathrm{N}_{2} \mathrm{O}$ emissions (Zschornack et al., p.1163). Concerning the potential of management systems to mitigate the emission of greenhouse gases, the emissions of $\mathrm{CO}_{2}$ and nitrogen oxides $\left(\mathrm{NO}_{\mathrm{x}}\right.$ and $\left.\mathrm{N}_{2} \mathrm{O}\right)$ are measured in the conventional and in no-tillage systems, with different cover crops in the Cerrado region (Carvalho et al., p.1213). Another study addresses the emissions of $\mathrm{N}_{2} \mathrm{O}$ in grassland, native cerrado, and in ICLF as affected by soil physical and chemical properties (Côrrea et al., p.1148). Finalizing this scale, there are reports on the impacts of the conversion of primary forest into a rubber tree plantation on soil physical, chemical, and biological attributes (Zaninetti et al., p.1061), as well as on the effects of biochar, combined with different levels of nitrogen fertilization, on $\mathrm{N}_{2} \mathrm{O}$ fluxes (Carvalho et al., p.1203).

The most specific scale in this section covers studies that evaluate both local ecosystems and the effects of the conversion of natural ecosystems into agricultural areas on soil physical, chemical, and biological 
attributes. The impact of the conversion of "murundu fields" to a no-tillage production system is assessed as to its effects on organic matter content and on soil aggregation (Souza et al., p.1194). The impact of the cultivation of a hydromorphic soil is also reported in a study in the Pampa biome, in which the effects of integrated production systems on soil macroporosity and soil fauna are evaluated (Carvalho et al., p.1131).

In a more punctual study, the evolution of soil physical conditions and of the root development of perennial grasses in a soil reconstructed after coal mining (Stumpf et al., p.1078), whose mined surfaces require the use of vegetation cover for the recovery of degraded areas, is presented.

\section{Soil and Production}

In this section of the Thematic Issue, soil is approached as a substrate for agricultural production, in which cropping systems are assessed by physical, chemical, and biological indicators of soil quality. Soil conservation, fertility, and water management are evaluated primarily in works conducted in two scales: the farming system scale and the "local" scale, in which more specific issues are discussed, related to soils of lowlands and of Coastal Tablelands, the use of biochar as a substrate for seedling production, and a contextualization on stable isotopes (Figure 6). In Figure 7, a word cloud (in Portuguese) is presented, drawn from the use frequency of the terms employed in the studies within the section.

In cropping systems, soil quality indicators subsidize soil management and conservation strategies to ensure the sustainability of the rural landscape. The sensitivity of soil quality indicators in no-tillage and conventional systems, and in the native cerrado vegetation, is assessed with the use of different databases (Stefanoski et al., p.1643). Rosset et al., p.1529, indicate which chemical fractions of soil organic matter discriminate more sensitively the management systems characterized by different implementation periods $(6,14$, and 22 years) of no-tillage. The relationship of soil organic matter (SOM) quality with cover crops and with the management of phosphate fertilization is evaluated by Souza et al., p.1667, who show that this fertilization in a prolonged period under no-tillage, associated with millet as a cover crop, promotes organic carbon accumulation in soil humic fractions. Melo et al., p.1511, study the humic, granulometric, and oxidizable fractions of SOM, as well as the soil contents of light organic matter and the stocks and contents of $\mathrm{C}$ and $\mathrm{N}$, in no-tillage and conventional systems.

Microbiological attributes, such as basal respiration, microbial biomass nitrogen, and microbial biomass carbon, show different dynamics in ICLF, crop-livestock integration (ICL), native cerrado vegetation, and continuous grazing, according to Oliveira et al., p.1501. Coser et al., p.1660, evaluate the effect of corn crops in monoculture and intercropped with forage on soil microbiological properties and on the availability of nitrogen under no-tillage, in the Cerrado. Regarding soil biology, the characterization of soil macrofauna is studied in grain production systems subjected to no-tillage and to conventional tillage systems, in soils with different textures, in the region of Matopiba (Santos et al., p.1466). The authors report that no-tillage provides greater species abundance and richness than conventional tillage, and identify different relationships of soil attributes with the different functional groups of soil macrofauna.

SOM physical fractions and the carbon management index (CMI), in an Oxisol cultivated with sugarcane, are reported after different periods of sugarcane implementation with conventional tillage (Kunde et al., p.1520). Still on the culture of sugarcane, the effects of the harvest, with or without straw burning, are assessed on soil chemical properties, on the contents and stocks of C and N, and on SOM quality (Signor et al., p.1438).

Physical indicators of soil quality, under different crop rotation systems and with different succession of crops, are studied by Seben Junior et al., p.1568. The authors also made a report on soil aggregation associated with the dynamics of $\mathrm{C}$ and $\mathrm{N}$ in these different cropping systems (Seben Junior et al., p.1652). The effect of soil management on its structure is also addressed in different agroecological managements, in which the formation process of biogenic, intermediate, and physiogenic aggregates are evaluated, as well as their stability and chemical attributes (Rossi et al., p.1677).

Apparent hydraulic conductivity is an attribute commonly associated with several indicators of soil quality and is examined in different cropping systems, in Oxisols with predominance of the sand fraction in their granulometry (Fontana et al., p.1457). The quality of the porous medium of an Inceptisol subjected to 
different uses is examined in a study in which a new $\mathrm{S}$ index - the Srelative index - is proposed to monitor the effects of management on soil physical quality (Assis Jr. et al., p.1575).

The soil physical quality associated with sugarcane productivity is studied with the use of scarification between planting rows (Sá et al., p.1610). In this sense, different straw collection levels after sugarcane harvest are assessed as to their effect on the mineralization of carbon, hemicellulose, cellulose, and lignin on the soil (Ramos et al., p.1492).
Studies related to soil quality indicators and to water availability are also subjects in this section. Several chemical and hydrophysical attributes of the soil related to water availability are evaluated in an irrigated coffee crop, using brachiaria as a cover crop in between the lines (Rocha et al., p.1476). The authors also discuss the effect of irrigation on carbon stock on soil surface layers. Soil physical quality is assessed in irrigated sugarcane crops in chronosequence with $5,7,8$, and 9 years of cultivation (Almeida et al., p.1539), and the effects of superficial straw deposition



Figure 6. Themes addressed in the section Soil and Production and their connections. Themes: 1, soil quality indicators (physical, chemical, and biological); 2, soil fertility management; 3, interface between the topics addressed in 1 and $5 ; 4$, interface between the topics addressed in 2 and 5 ; and 5, water availability. 
on soil quality indicators are considered beneficial. In addition, the effect of soil chemical and physical properties on forage production of palisade grass is analyzed in different agricultural integrated production systems (Bonini et al., p.1695).

Besides the studies addressing management effects on soil physical quality and on attributes related to water availability, other ones on soil fertility also stand out in this section. In a no-tillage system, the long-term effects of surface liming are evaluated on soil fertility, on mineral nutrition, and on the yield of soybean, in summer cultivation, and of oat and sorghum in succession (Costa et al., p.1633). Gurgel et al., p.1686, assess methods for estimating losses by

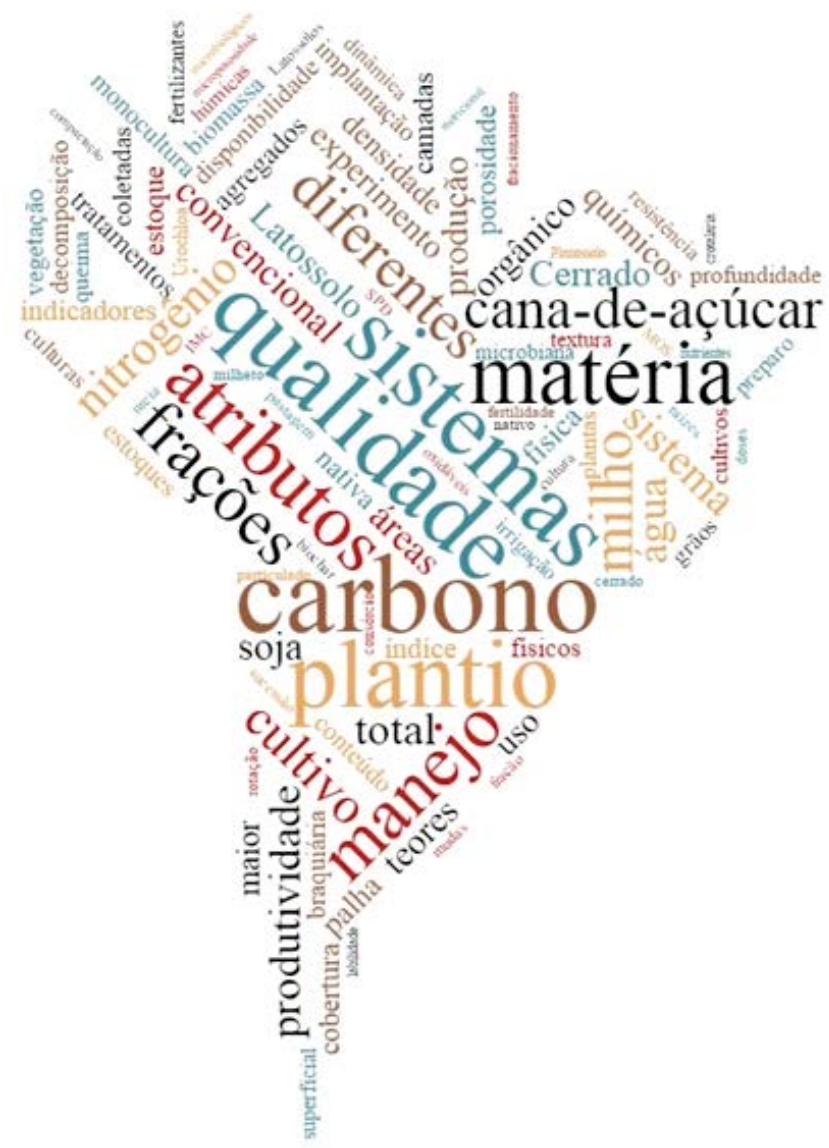

Figure 7. Word cloud, in Portuguese, drawn from the use frequency of the terms employed in the studies within the section Soil and Production. The major terms were: carbon, planting, quality, systems, attributes, management, fractions, sugarcane, crops, productivity, nitrogen, corn, conventional, organic, and matter.
$\mathrm{N}-\mathrm{NH}_{3}$ volatilization, as well as the ability of a set of mineral fertilizers mixed with urea, humic acids, and zeolite to mitigate these losses. The productivity and quality of common bean cultivated on grass straw and fertilized with nitrogen are evaluated under no-tillage (Amaral et al., p.1602).

In the interface between soil fertility management and nutrient availability, Ucker et al., p.1548, study the vertical movement of the potassium ion in a Quartzipsamment profile, under cultivation with sugarcane and different rainfall regimes, whereas Matos et al., p.1557, determine the critical levels and nutrient sufficiency ranges for oil palm using the following methods for the evaluation of plant nutritional status: diagnosis and recommendation integrated system (Dris) and compositional nutrient diagnosis (CND).

Albaqualf have been incorporated with increasing frequency to productive systems in the lowlands of Southern Brazil. The degradation of these soils has been reported as a result of human activities, particularly farming practices, highlighting the need for alternatives for the mitigation of soil compaction and of soil structure disruption, with studies evaluating soil physical quality, water availability, and overall quality. In this section, the studies with these themes are analyzed in a more local scale. Pinto et al., p.1584, assess the productivity offlooded and sprinkler-irrigated rice in these soils, as a result of water availability and of soil physical and chemical properties. Furthermore, the authors quantify the water spent with the sprinkler and flood irrigation systems, as well as rice productivity, due to soil physical and chemical properties. Ribeiro et al., p.1484, observe that soybean cultivation under no-tillage, in Albaqualf, promotes microporosity, water storage and availability, when compared with the conventional system. Improving Albaqualf physical quality under no-tillage is also discussed by Reis et al., p. 1623 .

Also within this local-scale analysis, cohesive soils, characteristic of the geomorphological unit Coastal Tablelands, are studied regarding the spatial variability of their physical attributes under no-tillage and conventional tillage systems (Ribeiro et al., p.1699).

In this section, there is also a review on the topic of stable isotopes - from production to consumption -, which traces the dynamics of $\mathrm{C}, \mathrm{N}$, and $\mathrm{S}$ in Brazilian agroecosystems, highlighting the contributions of Brazilian scientists for tracking fluxes of carbon 
and nutrients, for the synthesis and evaluation of the effectiveness of marked fertilizers, and for the authentication of food and beverages (Chalk, p.1039). Besides this review, the section has a study on the use of isotopes for assessing both the effect of the inoculation of nitrogen-fixing bacteria on sugarcane productivity and on the isotopic dilution of $15 \mathrm{~N}$, as well as the $15 \mathrm{~N}$ isotopic dilution naturally associated with this culture (Schultz et al., p.1594). Another theme with a punctual interest is the use of biochar as a substrate to evaluate the development and quality of teak seedlings (Tectona grandis) (Rezende et al., p.1449).

\section{Final Considerations}

This Thematic Issue is composed of 71 articles, of which 17 are presented in the Soil and Planning section, 23 in the Soil and Environment section, and 31 in the Soil and Production section. The articles presented in these sections express the current state and the research trends in the various subjects assessed, signposting the demands and challenges for the knowledge of the resource Soil as an Integrating Factor between Environmental Components and Agricultural Production. We are grateful to all from the scientific community engaged in building this Issue. 